\begin{tabular}{|c|l|}
\hline Title & Concise [4+3] cycloaddition reaction of pyrroles leading to tropinone derivatives \\
\hline Author(s) & Fuchigami, Ryuichi; Namba, Kosuke; Tanino, Keiji \\
\hline Citation & $\begin{array}{l}\text { Tetrahedron Letters, 53(43), 5725-5728 } \\
\text { https://doi.org/40.1016/.tetlet.2012.07.130 }\end{array}$ \\
\hline Issue Date & 2012-10-24 \\
\hline Doc URL & http://hdl.handle.net/2115/50425 \\
\hline Type & article (author version) \\
\hline File Information & TL53-43_5725-5728.pdf \\
\hline
\end{tabular}

Instructions for use 


\section{Graphical Abstract}

To create your abstract, type over the instructions in the template box below.

Fonts or abstract dimensions should not be changed or altered.

\begin{tabular}{l}
$\begin{array}{l}\text { A Concise [4+3] Cycloaddition Reaction of } \\
\text { Pyrroles Leading to Tropinone Derivatives } \\
\text { Ryuichi Fuchigami, Kosuke Namba, and Keiji Tanino* } \\
\text { Hokkaido University, Sapporo, 060-0810, Japan }\end{array}$ \\
\hline
\end{tabular}




\title{
Concise [4+3] Cycloaddition Reaction of Pyrroles Leading to Tropinone Derivatives
}

\author{
Ryuichi Fuchigami $^{\mathrm{a}}$, Kosuke Namba ${ }^{\mathrm{b} *}$, and Keiji Tanino ${ }^{\mathrm{b}^{*}}$ \\ ${ }^{a}$ Graduate School of Chemical Sciences and Engineering, Hokkaido University, Sapporo 060-0810, Japan \\ ${ }^{\mathrm{b}}$ Department of Chemistry, Faculty of Science, Hokkaido University, Sapporo 060-0810, Japan
}

\begin{abstract}
A concise [4+3] cycloaddition reaction of pyrroles with 2-(silyloxy)allyl cations has been developed. The oxyallyl cations stabilized with a methylthio group or geminal methyl groups were generated from the corresponding allylic alcohols under the influence of a Brönsted acid $\left(\mathrm{Tf}_{2} \mathrm{NH}\right)$, respectively. The use of $\mathrm{N}$-nosyl-protected pyrroles as the four-carbon unit was found to give tropinone derivatives in high yield.
\end{abstract}

Tropane alkaloids, which comprise a large family of natural products, have received a great deal of attention due to their variety of pharmacological activities and structural diversity. ${ }^{1}$ In particular, atropine, cocaine, and scopolamine are famous lead compounds of pharmaceuticals, ${ }^{2}$ and stemofoline $^{3}$ and himandrine ${ }^{4}$ are also known as a class of challenging synthetic targets. One of the most powerful synthetic approaches to tropane scaffold may be a [4+3] cycloaddition reaction of pyrroles with oxyallyl cations, giving rise to tropinones (Scheme 1). ${ }^{5}$

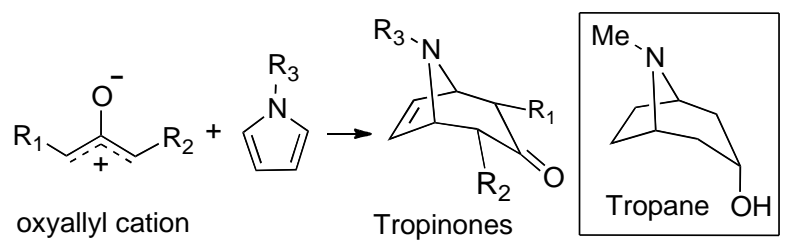

Scheme 1. The [4+3] cycloaddition reaction of oxyallyl cation with pyrrole derivative.

While there are a number of reports concerning the [4+3] cycloaddition reactions of furans or cyclopentadienes, ${ }^{5}$ the use of pyrroles as four-carbon units is generally difficult due to competition with the Friedel-Crafts type reaction. ${ }^{6}$ The oxyallyl cation species applicable to pyrroles thus far have been confined to those generated from $\alpha, \alpha$ dihaloketones ${ }^{7}$ or allenamides ${ }^{8}$. On the other hand, one of the authors reported the regio- and stereoselective [3+2] cycloaddition reactions using allyl acetates $\mathbf{1 a}$ and $\mathbf{1 b}$ as a three-carbon unit (Scheme 2). ${ }^{9}$ Under the influence of $\mathrm{EtAlCl}_{2}$, allyl acetate $\mathbf{1}$ reacted with alkene $\mathbf{2}$ to afford cyclopentanone $\mathbf{3}$ in good yield. In this reaction, the methylthio group of $\mathbf{1}$ plays an important role in stabilizing the allyl cation species $\mathbf{A}$ as well as controlling the regio selectivity of the cycloadducts. ${ }^{10}$
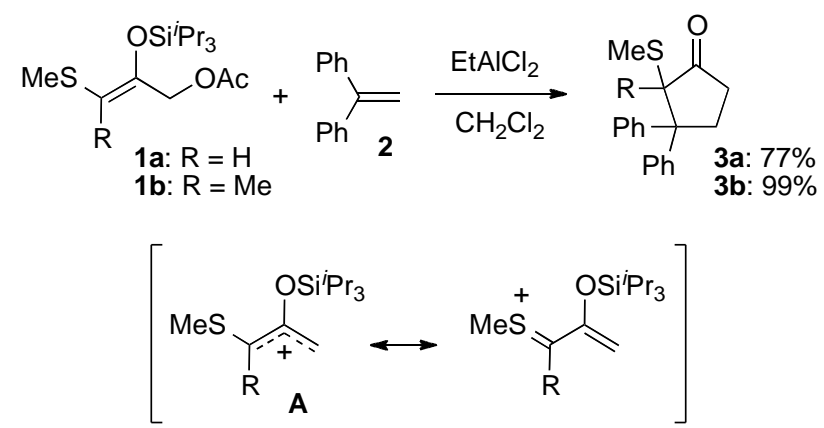

Scheme 2. The [3+2] cycloaddition reaction using sulfur-stabilized siloxyallyl cations.

These results led us to examine the [4+3] cycloaddition reaction of 1 with pyrrole derivatives. Herein, we describe concise [4+3] cycloaddition reactions of 2-(silyloxy)allyl cations stabilized by a methylthio group or gem-dialkyl groups with pyrroles having various substituents.

The 2-nitrobenzenesulfonyl (nosyl, Ns) group ${ }^{11}$, which can be removed under mild conditions, was chosen for protection of the nitrogen atom. The reactions of $N$-nosyl pyrrole (4) with 1a or its derivatives under acidic conditions are summarized in Table 1.

\footnotetext{
Keywords: tropinone, [4+3] cycloaddition reaction, pyrroles, oxyallyl cation, sulfur-stabilized cation

* Corresponding author. Tel.: +81-11-706-2703; fax: +81-11-706-4920; e-mail: namba@mail.sci.hokudai.ac.jp

* Corresponding author. Tel.: +81-11-706-2705; fax: +81-11-706-4920; e-mail: ktanino@ sci.hokudai.ac.jp
} 
Table 1. The reactions of $\mathbf{4}$ with three-carbon units $\mathbf{1}$ promoted by an acid. $^{\mathrm{a}}$

\begin{tabular}{|c|c|c|c|c|}
\hline$\underbrace{N}_{4}$ & $\frac{\underset{-78{ }^{\circ} \mathrm{C}, 1 \mathrm{~h}}{\mathrm{CH}_{2} \mathrm{Cl}_{2}}}{\text { acid }}$ & Mes, & & $\frac{11}{6}$ \\
\hline \multirow{2}{*}{ entry } & \multirow{2}{*}{ 1: $X$} & \multirow{2}{*}{ acid } & \multicolumn{2}{|c|}{ yield $(\%)^{\mathrm{b}}$} \\
\hline & & & 5 & 6 \\
\hline 1 & 1a: OAc & $\mathrm{EtAlCl}_{2}$ & 15 & 0 \\
\hline 2 & 1a: OAc & $\mathrm{Tf}_{2} \mathrm{NH}$ & 34 & 27 \\
\hline 3 & 1c: $\mathrm{OCO}_{2} \mathrm{Me}$ & $\mathrm{Tf}_{2} \mathrm{NH}$ & 54 & 0 \\
\hline 4 & 1d: $\mathrm{OH}$ & $\mathrm{Tf}_{2} \mathrm{NH}$ & 85 & 5 \\
\hline 5 & 1d: $\mathrm{OH}$ & $\mathrm{TfOH}$ & 41 & 38 \\
\hline
\end{tabular}

$\mathrm{R}=\mathrm{CH}_{2} \mathrm{C}(\mathrm{O}) \mathrm{CH}_{2} \mathrm{SMe}$

${ }^{\text {a }}$ Conditions: $N$-nosyl pyrrole $(0.10 \mathrm{mmol}), \mathbf{1}(0.30 \mathrm{mmol})$, acid $(0.60$ $\mathrm{mmol}), \mathrm{CH}_{2} \mathrm{Cl}_{2}(0.2 \mathrm{M})$. ${ }^{\mathrm{b}}$ isolated yield.

While the reaction of $\mathbf{4}$ with $\mathbf{1 a}$ promoted by $\mathrm{EtAlCl}_{2}$ led to formation of cycloadduct 5 in $15 \%$ yield (entry 1$),{ }^{12}$ the use of a Brönsted acid was found to be more effective for the desired transformation. Thus, under the influence of trifluoromethanesulfonimide $\left(\mathrm{Tf}_{2} \mathrm{NH}\right)$, tropinone $\mathbf{5}$ was obtained in $34 \%$ yield along with $27 \%$ of 6 (entry 2). Interestingly, the $\mathrm{Tf}_{2} \mathrm{NH}$-promoted reaction of $\mathbf{4}$ with carbonate 1c gave $54 \%$ of $\mathbf{5}$ (entry 3), and the yield increased to $85 \%$ with alcohol $\mathbf{1} \mathbf{d}^{9}$ (entry 4). ${ }^{13}$ On the other hand, the use of trifluoromethanesulfonic acid (TfOH) instead of $\mathrm{Tf}_{2} \mathrm{NH}$ in the reaction of $\mathbf{4}$ and $\mathbf{1 d}$ resulted in decrease of $\mathbf{5}$ (entry 5), probably because of the low solubility of $\mathrm{TfOH}$ in dichloromethane.

It is noteworthy that tropinone $\mathbf{5}$ was produced as a single diastereomer which underwent partial isomerization to afford epi-5 by chromatography on silica gel. The stereostructure of these compounds was determined by the NOE experiments, indicating that $\mathbf{5}$ possesses the methylthio group and the nitrogen atom on the opposite face of the seven-membered ring (endo-type stereochemistry). The methylthio group of $\mathbf{5}$ was easily removed by treating with $\mathrm{PPh}_{3}$ and $p$-toluenesulfonic acid $(\mathrm{TsOH})$ to give tropinone $\mathbf{7}$ in good yield, according to the desulfurization protocol of Durst (Scheme 3). ${ }^{14}$ Thus, the [4+3] cycloaddition reaction using sulfur-stabilized 2(silyloxy)allyl cation is proven to be a concise and effective method for the preparation of tropinone derivatives. ${ }^{15}$

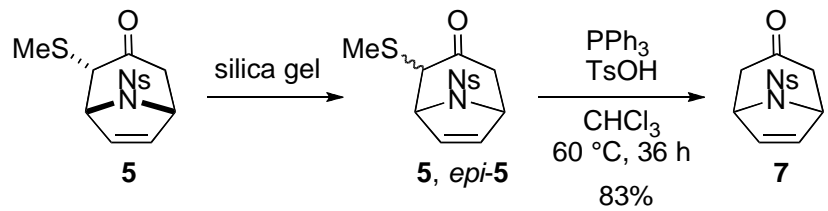

Next, the [4+3] cycloaddition reaction of pyrroles possessing various protecting groups $(\mathrm{X})$ with allyl alcohol 1d were examined (Table 2). While $N$-( $p$-toluenesulfonyl) and $N$-methanesulfonyl pyrroles Ts-4 and Ms-4 afforded the corresponding tropinones Ts-5 and Ms-5 in low yields, respectively (entries 2 and 3), $N$-benzyloxycarbonyl (Cbz), $N$-acetyl (Ac), $N$-benzyl (Bn), and unsubstituted pyrroles failed to undergo the cycloaddition reaction (entries 4-7). These results suggest that the electron-withdrawing inductive effect of the protecting group (Ns > Ts, Ms > Ac, $\mathrm{Cbz})$ is of more significance than the steric bulkiness. ${ }^{16}$

Table 2. Comparison of the protecting group on pyrrole. ${ }^{a}$

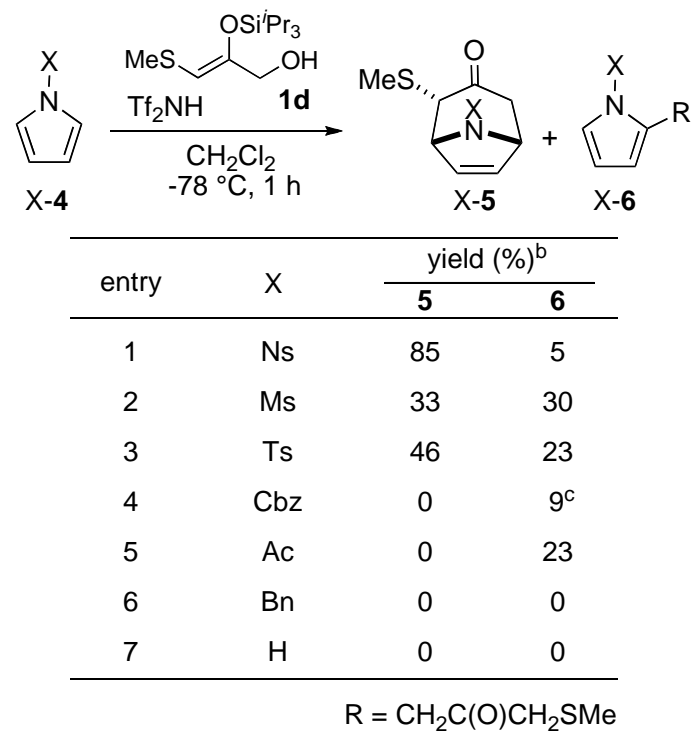

${ }^{\text {a }}$ Conditions: pyrrole X-4 $(0.10 \mathrm{mmol}), \mathbf{1 d}(0.30 \mathrm{mmol}), \mathrm{Tf}_{2} \mathrm{NH}(0.60$ $\mathrm{mmol}), \mathrm{CH}_{2} \mathrm{Cl}_{2}(0.2 \mathrm{M}) .{ }^{\mathrm{b}}$ isolated yield. ${ }^{\mathrm{N}} \mathrm{NMR}$ yield using $\mathrm{CHBr}_{3}$ as an internal standard.

Having established the suitable conditions of the [4+3] cycloaddition reaction, the scope of the tropinone synthesis was examined (Table 3 ). Although the reaction of $N$-nosyl2-methylpyrrole (8) led to formation of the Friedel-Crafts product 13 (entry 1), 3-methylpyrrole (9) underwent the desired [4+3] cycloaddition reaction at $-60{ }^{\circ} \mathrm{C}$ to afford tropinone 14 in $71 \%$ yield as a single product (entry 2). The configuration of $\mathbf{1 4}$ and stereochemical relationship between the methyl group and the methylthio group were determined by the ${ }^{1} \mathrm{H}-{ }^{1} \mathrm{H}$ COSY and the NOE experiments. Similarly, tropinone $\mathbf{1 5}$ was obtained from the corresponding pyrrole $\mathbf{1 0}$ in a regio- and stereoselective manner, albeit in low yield due to the instability of the vinyl bromide moiety. ${ }^{17}$ 
Table 3. Substrate scope in the $[4+3]$ cycloaddition reactions.

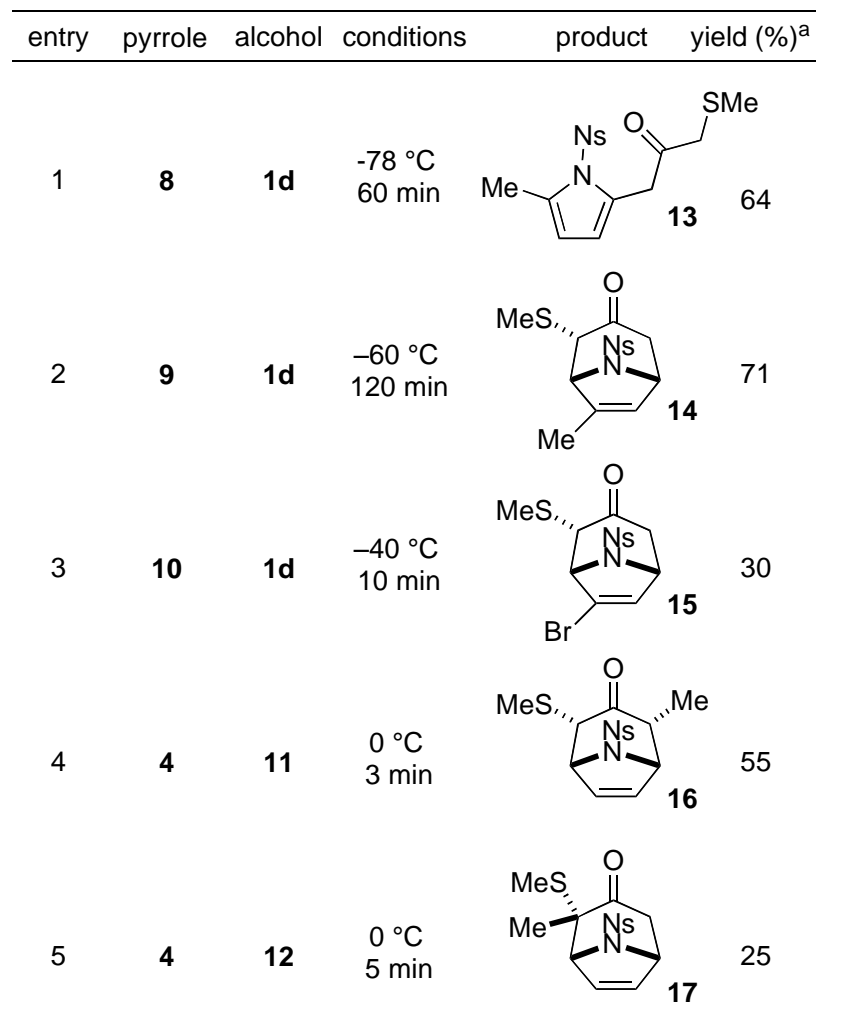<smiles>Cc1ccn(N)c1</smiles>

Conditions: $N$-nosyl pyrrole $(0.10 \mathrm{mmol})$, allyl alcohol $(0.30 \mathrm{mmol})$, $\mathrm{Tf}_{2} \mathrm{NH}(0.60 \mathrm{mmol}), \mathrm{CH}_{2} \mathrm{Cl}_{2}(0.2 \mathrm{M}),{ }^{\mathrm{a}}$ isolated yield. ${ }^{\mathrm{b}}$ The reaction was conducted at $-78^{\circ} \mathrm{C}$.

The reaction of methyl-substituted three-carbon unit $\mathbf{1 1}$ with pyrrole $\mathbf{4}$ at $0{ }^{\circ} \mathrm{C}$ afforded the desired cycloadduct 16 in 55\% yield. Three-carbon unit $\mathbf{1 2}$ having a methyl group at the other side also gave cycloadduct $\mathbf{1 7}$ as a single regio and stereoisomer, while the yield was low.

Next, the stabilizing effect of a methylthio group on the 2(silyloxy)allyl cation was compared with that of an alkyl group (Table 4). The reaction of allyl alcohol 18 with 4 under the influence of $\mathrm{Tf}_{2} \mathrm{NH}$ gave neither cycloadduct 7 nor a Friedel-Crafts type product (entry 1), and allyl alcohol 19 possessing a methyl group instead of the methylthio group of 1d also failed to undergo the [4+3] cycloaddition reaction (entry 2 ). On the other hand, the use of gem-dimethyl-substituted derivative $\mathbf{2 0}$ led to formation of the desired cycloadduct $\mathbf{2 2}$ in 54\% yield (entry 3 ). These results indicate that a gem-dimethyl group is as effective as a methylthio group in stabilizing a 2-(silyloxy)allyl cation, while a single methyl group of $\mathbf{1 9}$ is not sufficient for this purpose. Furthermore, we later found that 1,1,1,3,3,3hexafluro-2-propanol (HFIP) is a better solvent for the reaction of gem-dimethyl-substituted analog $\mathbf{2 0}$, and the yield of 22 was increased to $67 \%$ (entry 3 ). ${ }^{18}$ In contrast to the reaction of 2-methylpyrrole $\mathbf{8}$ with alcohol $\mathbf{1 d}$ which gave only substituted pyrrole $\mathbf{1 3}$ (entry 1 in Table 3), cycloadduct $\mathbf{2 3}$ was obtained by the use of $\mathbf{2 0}$ as the threecarbon unit (entry 4). It is noteworthy that the regiochemical outcome of the reaction of alcohol $\mathbf{2 0}$ is also different from that of the sulfur-containing alcohol $\mathbf{1 d}$. Thus, for the reactions with 3-methylpyrrole 9, alcohol $\mathbf{2 0}$ afforded a 1:1 regioisomeric mixture of cycloadducts $\mathbf{2 4 a}$ and $24 \mathrm{~b}$ in $65 \%$ yield (entry 5), while the use of $1 \mathrm{~d}$ resulted in formation of cycloadduct $\mathbf{1 4}$ as a single regioisomer (entry 2 in Table 3 ).

Table 4. The [4+3] cycloaddition reactions of $N$-nosyl pyrroles with siloxyallyl alcohol derivatives having no methylthio group.

entry pyrrole alcohol

Reaction conditions: $N$-nosyl pyrrole $(0.10 \mathrm{mmol})$, allyl alcohol $(0.30$ $\mathrm{mmol}), \mathrm{Tf}_{2} \mathrm{NH}(0.60 \mathrm{mmol})$, HFIP $(0.2 \mathrm{M}), 0{ }^{\circ} \mathrm{C}, 30 \mathrm{~min} .{ }^{\mathrm{a}}$ Isolated yield. ${ }^{\mathrm{b}}$ The reaction was conducted in dichloromethane at $0{ }^{\circ} \mathrm{C}$.

Finally, the utility of the present [4+3] cycloaddition reaction was demonstrated through the synthesis of tricyclic compound $\mathbf{2 8}$, possessing a common framework with biologically active natural products such as Daphyniphyllum alkaloids. ${ }^{19}$ Ketone 26, which was 
prepared from pyrrole 25 and alcohol 20 via a [4+3] cycloaddition reaction, was converted to the corresponding enol silyl ether 27. Treatment of $\mathbf{2 7}$ with silver (I) trifluoroacetate $^{20}$ effected the intramolecular alkylation reaction to provide the desired tricyclic compound $\mathbf{2 8}$ in $46 \%$ yield from ketone 26 .

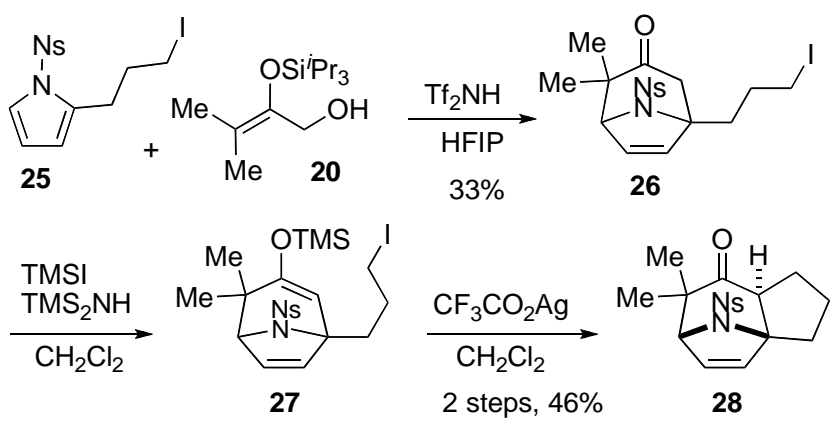

Scheme 4. Synthesis of tricyclic ketone 28 via a [4+3] cycloaddition reaction.

In conclusion, the [4+3] cycloaddition reaction of pyrroles leading to various tropinones was developed. ${ }^{20}$ The use of $\mathrm{N}$-nosyl pyrrole derivatives was found to afford the desired cycloadducts in good yields. The 2-(silyloxy)allyl cation was generated by treating the corresponding allyl alcohol with $\mathrm{Tf}_{2} \mathrm{NH}$, while the cation-stabilizing effect of a methylthio group or a gem-dimethyl group was essential for generation of the reactive species. The present [4+3] cycloaddition protocol provides a powerful method for constructing substituted tropane skeleton, and the applications to the synthesis of complex natural products are currently underway in our laboratory. ${ }^{\dagger}$

\section{Acknowledgments}

This work was partially supported by the Global COE program (Project No. B01: Catalysis as the Basis for Innovation in Material Science) and Grant-in-Aid for Scientific Research on Innovative Areas (Project No. 2105: Organic Synthesis Based on Reaction Integration and No. 2301: Chemical Biology of Natural Products) from the Ministry of Education, Culture, Sports, Science, and Technology, Japan.

\section{References}

1. (a) Pollini, G. P.; Benetti, S.; De Risi, C.; Zatirato, V. Chem. Rev. 2006, 106, 2434-2454. (b) Singh, S. Chem. Rev. 2000, $100,925$.

\footnotetext{
${ }^{\dagger}$ OLE: Object Linking and Embedding; a program-integration technology you can use to share information between programs. All of the Office programs support OLE, so you can share information through linked and embedded objects. For instance you can import an Excel ${ }^{\circledR}$ graph into Word ${ }^{\circledR}$ by using 'Paste special....' on the 'Edit' menu or, essentially the same, using the option on the 'Tables and figures' menu.
}

2. (a) WHO Model List of Essential Medicines. Warld Health Organization. March 2005. (b) Putcha, L.; Cintrón, N. M.; Tsui, J.; Vanderploeg, J. M.; Kramer, W. G. Pharmaceutical Research 1989, 6, 481-485. (c) Carroll, F. I.; Lewin, A. H.; Boja, J. W.; Kuhar, M. J. J. Med. Chem. 1992, 35, 969-981.

3. Irie, H.; Masaki, N.; Ohno, K.; Osaki, K.; Taga, T.; Uyeo, S. J. Chem. Soc. Chem. Commun. 1970, 1066-1068.

4. Binns, S. V.; Dustan, P. J.; Guise, G. B.; Holder, G. M.; Hollis, A. F.; McCredie, R. S.; Pinhey, J. T.; Prager, R. H.; Rasmussen, M.; Ritchie, E.; Taylor, W. C. Aust. J. Chem. $1965,18,569$.

5. (a) Noyori, R.; Hayakawa, Y. Organic Reactions; Paquette, L. A. Ed.; John Wiley \& Sons, Inc; New York, 1983, 29, 163344. (b) Rigby, J. H.; Pigge, F. C. Organic Reactions; Paquette, L. A. Ed.; John Wiley \& Sons, Inc; New York, 1997, 51, 351-476.

6. Paparin, J.-L.; Crévisy, C.; Toupet, L.; Grée, R. Eur. J. Org. Chem. 2000, 3909-3918.

7. For recent examples of the $[4+3]$ cycloaddition reaction of pyrroles with oxyallyl cation generated from $a, a^{\prime}$ dihaloketones not cited in ref. 5, see (a) Paparin, J.-L.; Crévisy, C.; Grée, R. Tetrahedron Lett. 2000, 41, 2343-2346. (b) Montana, A. M.; Grima, P. M. Tetrahedron Lett. 2001, 42, 7809-7813. (c) Cramer, N.; Laschat. S.; Baro, A.; Frey, W. Synlett 2003, 2175-2177. (d) Hodgson, D. M.; Paruch, E. Tetrahedron 2004, 60, 5185-5199. (d) MaGee, D. I.; Godineau, E.; Thornton, P. D.; Walters, M. A.; Sponholtz, D. J. Eur. J. Org. Chem. 2006, 3667-3680. (e) Kulkarni, K.; Zhao, A. Y.; Purcell, A. W.; Perlmutter, P. Synlett 2008, 2209-2212. (f) Hodgson, D. M.; Shelton, R. E.; Moss, T. A.; Dekhane, M. Org. Lett. 2010, 12, 2834-2837. (g) Xia, Y.; Chackalamannil, S.; Greenlee, W. J.; Jayne, C.; Neustadt, B.; Stamford, A.; Vaccaro, H.; Xu, X.; Baker, H.; O’Neill, K.; Woods, M.; Hawes, B.; Kowalski, T. Bioorg. Med. Chem. Lett. 2011, 21, 3290-3296.

8. Antoline, J. E.; Hsung, R. P.; Huang, J.; Song, Z.; Li, G. Org. Lett. 2007, 9, 1275-1278.

9. Masuya, K.; Domon, K.; Tanino, K.; Kuwajima, I. J. Am. Chem. Soc. 1998, 120, 1724-1731.

10. For recent reviews on the [4+3] cycloaddition reaction using heteroatom-substituted oxyallyl cations, see (a) Harmata, M. Adv. Synth. Catal. 2006, 348, 2297-2306. (b) Harmata, M. Chem. Commun. 2010, 46, 8904-8922.

11. For review, see: Kan, T.; Fukuyama, T. Chem. Commun. 2004, 353-359.

12. The yield of $\mathbf{5}$ was substantially increased up to $66 \%$ when the reaction temperature was elevated to $-40{ }^{\circ} \mathrm{C}$.

13. The reaction using catalytic amount of $\mathrm{Tf}_{2} \mathrm{NH}(10 \mathrm{~mol} \%)$ did not proceeded at $-78{ }^{\circ} \mathrm{C}$, and the nosylpyrrole 4 (quant) and three carbon unit $\mathbf{1 d}(90 \%)$ were recovered after $1 \mathrm{~h}$. The similar reaction with increasing temperature induced only decomposition of $\mathbf{1 d}$.

14. Connolly, T. J.; Durst, T. Synlett 1996, 663-664.

15. Typical procedure: To a solution of $\mathrm{Tf}_{2} \mathrm{NH}(169 \mathrm{mg}, 0.60$ $\mathrm{mmol})$ in $\mathrm{CH}_{2} \mathrm{Cl}_{2}(0.25 \mathrm{~mL})$ was added a mixture of $\mathbf{1 d}(83$ $\mathrm{mg}, 0.30 \mathrm{mmol})$ and $4(25.2 \mathrm{mg}, 0.1 \mathrm{mmol})$ in $\mathrm{CH}_{2} \mathrm{Cl}_{2}(0.25$ $\mathrm{mL}$ ) at $-78{ }^{\circ} \mathrm{C}$. After the mixture was stirred at $-78{ }^{\circ} \mathrm{C}$ for $1 \mathrm{~h}$, the reaction was quenched with a $3 \mathrm{M}$ aqueous $\mathrm{NaOH}$ solution at $-78{ }^{\circ} \mathrm{C}$. The mixture was extracted with $\mathrm{CH}_{2} \mathrm{Cl}_{2}$ (x2), and the combined organic layers were washed with brine, dried over $\mathrm{MgSO}_{4}$, filtered, and concentrated under reduced pressure. The residue was purified by flash silica gel column choromatography (elution with hexane/ethyl acetate $=3 / 1$ to $2 / 1)$ to give 5 (30 $\mathrm{mg}, 85 \%)$ as a pale brown solid.

16. Decomposition and polymerization of nosyl-protected pyrroles were not observed even in the excess amount of strong acid such as $\mathrm{Tf}_{2} \mathrm{NH}$. The [4+3] cycloadducts were also 
sufficiently stable until completion of the reaction, although the prolonged period of the reaction induced decomposition of cycloadducts. The strong electron-withdrawing inductive effect of $N$-nosyl group was considered to suppress the retroMannich reaction leading to Friedel-Crafts type by-products and decomposition. Decomposition and polymerization of pyrroles were observed when other protecting groups, not involving sulfonamides, were used.

17. After quenching the reaction, $\mathbf{1 5}$ was stable enough to be purified by column chromatography and stored for several months in the freezer.

18. The use of HFIP as a solvent for the reaction of methylthiosubstituted analog 1d was not effective.

19. For recent review on the Daphyniphyllum alkaloids, see: Kobayashi, J.; Kubota, T. Nat. Prod. Rep. 2009, 26, 936-962.

20. Mitachi, K.; Yamamoto, T.; Kondo, F.; Shimizu, T. Miyashita, M.; Tanino, K. Chem. Lett. 2010, 39, 630-632.

\section{Supplementary Material}

Supplementary data (complete experimental details and spectroscopic characterization of all new compounds) associated with this article can be found, in the online version 